Law \& Economics Working Papers

Law \& Economics Working Papers Archive:

2003-2009

Year 2009

\title{
Between Formulary Apportionment and the OECD Guidelines: A Proposal for Reconciliation
}

Reuven S. Avi-Yonah

University of Michigan Law School, aviyonah@umich.edu 


\title{
BETWEEN FORMULARY APPORTIONMENT AND THE OECD GUIDELINES: A PROPOSAL FOR RECONCILIATION
}

\author{
Reuven S. Avi-Yonah ${ }^{1}$
}

\section{A Historical Introduction.}

In the last thirty years, a debate has been raging in international tax circles between advocates of the OECD transfer pricing guidelines and the arm's length standard (ALS) they embody and advocates of formulary apportionment (FA). ${ }^{2}$ This issue can be traced as far back as the 1930s, when the ALS was originally conceived of and introduced into the first model treaties. ${ }^{3}$ However, before the 1960s there was not much transfer pricing enforcement and the ALS was rather indeterminate in the absence of concrete transfer pricing methods. FA, in the meantime, was applied by the US states but was not seriously considered as a method of resolving transfer pricing at the international level.

In 1962 the US House of Representatives passed a bill that would for the first time have applied FA to address transfer pricing at the federal level. This was in the context of increasing transfer pricing concerns evidenced by the Dupont case (which began in the 1950s, even though it was not decided until 1979) and the enactment of Subpart F, which at least in part responded to such concerns. However, Stanley Surrey, the new Assistant Secretary for Tax Policy and a great believer in the ALS, thought he had a better approach, and the ultimate legislation merely authorized the Treasury to write regulations under IRC 482 implementing the ALS.

The regulations Surrey authored were eventually finalized in 1968 and for the first time imbued the ALS with practical meaning by formulating the three classical methods of Comparable Uncontrolled Price (CUP), cost plus and resale price, all of which depended on finding comparable uncontrolled transactions to those engaged in by the related parties. These regulations were the basis for US transfer pricing litigation in the 1970s and 1980s, as well as the basis for the original OECD Transfer Pricing Guidelines issued in 1977.

The problem that gradually became evident was that the traditional methods did not work in the majority of transfer pricing cases. The General Accounting Office did a study in the early 1990s that indicated that in over $90 \%$ of the cases the three traditional methods could not be applied because comparables could not be found. ${ }^{4}$ Moreover, after

\footnotetext{
${ }^{1}$ Irwin I. Cohn Professor of Law and Director, International Tax LLM, the University of Michigan.

${ }^{2}$ Langbein, Stanley I. 1986. “The Unitary Method and the Myth of Arm’s Length.” Tax Notes 30: 625.

3 Avi-Yonah, Reuven. 2006. “The Rise and Fall of Arm's Length: A Study in the Evolution of U.S. International Taxation.” Finance and Tax Law Review 9:310 (updated version of article from 1995 Virginia Tax Review, 15:89).

${ }^{4}$ General Accounting Office, International Taxation Problems Persist in Determining Tax Effects of Intercompany Prices, GAO/GGD 92-89 (1992).
} 
winning Dupont in 1979 the IRS lost every single major transfer pricing case it litigated between 1980 and 1995, including cases against all the US pharmaceutical companies and many other US multinationals. The major reason for these losses was that the courts refused to accept the comparables used by the IRS under the traditional methods, and either accepted bogus comparables manufactured by the taxpayers, or more frequently simply made up a transfer price that also favored the taxpayer. ${ }^{5}$

In the meantime, FA became more prominent because the US Supreme Court twice (in 1984 and 1993) upheld California's use of the method to apportion the worldwide income of multinationals doing business in the state. The multinationals and their supporters argued that FA was inconsistent with the internationally accepted ALS and therefore California's reliance on it was unconstitutional, but the Court rejected this argument, once for a US-based and again for a foreign-based multinational. As a result, the literature from the early 1990s is full of debates between advocates of ALS ad FA. ${ }^{6}$

Ultimately, the result was a compromise. In 1995, the US adopted new transfer pricing regulations that incorporated two new methods, the Comparable Profit Method (CPM) and Profit Split, which relied much less on comparables (CPM uses comparability very loosely and in Profit Split the residual is not allocated based on comparables). The OECD followed suit and amended the Transfer Pricing Guidelines to include the new methods, which it calls the Transactional Net Margin Method (TNMM) and Profit Split, although in deference to opponents of FA it still rejected FA and emphasized that the traditional methods were to be preferred to the new ones. ${ }^{7}$ It also changed the name CPM to TNMM to emphasize that it does not involve a global profit allocation but rather allocation for the particular transaction, since the former is closer to FA.

Nevertheless, it is clear that by moving beyond traditional comparability, the OECD was moving closer to accepting FA. Once you do not base the ALS on finding comparables, then it is not very meaningful to say that a particular method is or is not compatible with the ALS, because if there are no comparables you cannot prove that the result reached by that method was not what unrelated parties would have done at arm's length. That is why it is possible to argue that FA is compatible with Article 7 of the OECD model treaty, which focuses on the results that unrelated parties would have reached and permits in Art. 7(4) the use of formulas as long as the result is compatible with the ALS. ${ }^{8}$ And that is why a group of senior tax officials from OECD member

${ }^{5}$ Avi-Yonah (2006), supra.

${ }^{6}$ Avi-Yonah, supra (1995); Bucks, Dan R., and Michael Mazerov. 1993. "The State Solution to the Federal Government's International Transfer Pricing Problem.” National Tax Journal. 46(3). 385-92; Cofill, Eric J. \& Prentice Wilson Jr.. 1993. “Federal Formulary Apportionment As An Alternative To Arm’s Length Pricing: From The Frying Pan To The Fire?.” Tax Notes, May 15; Wilkins, William J. \& Kenneth W. Gideon (1994). "Memorandum to Congress: You Wouldn't Like Worldwide Formulary Apportionment.” Tax Notes 69:1259.

7 OECD (1995). Organization for Economic Cooperation and Development, Transfer Pricing Guidelines for Multinational Enterprises and Tax Administrations.

8 That argument is developed in Avi-Yonah and Clausing (2008), Art. 7 (Business 
countries concluded in 1993 that the distinction between the ALS and FA was largely a matter of semantics, not substance. ${ }^{9}$

The ALS/FA debate died down somewhat after the adoption of the 1995 regulations and the new OECD guidelines because everyone was waiting to see whether the issue had been resolved. However, while there have been few decided cases, it is clear by now that the transfer pricing problem is as bad as it ever was. That is why my coauthors Kimberly Clausing and Michael Durst and I have recently re-proposed adopting FA. $^{10}$

However, it is clear from the reactions we received that it is unlikely we will persuade advocates of the ALS and in particular the OECD that FA is the way forward (although this may change if the Obama Administration were to press the issue, or if the EU adopts CCCTB). Thus, I would like to propose a compromise: Use FA in the context of the ALS. Specifically, I would suggest using FA to allocate the residual profit in the Profit Split method.

The rest of this article is devoted to (a) explaining the drawbacks of ALS as currently applied, (b) developing the above proposal, and (c) concluding with a plea for further discussion by both sides of the FA/ALS debate.

\section{The Problems of the ALS. ${ }^{11}$}

At the heart of the ALS system, with its reliance on estimated "arm's length" prices, is the assumption that each affiliated company within the group transacts with the other members of the group in the same way that it would transact if the members were unrelated. That central assumption defies reality, and it is not surprising that a system of “arm’s length” pricing cannot yield sensible results.

Profits), in Michael Lang et al., Source vs. Residence. The argument that FA is compatible with the treaties assumes that in most cases subsidiaries can be treated as dependent agent PEs and therefore Art. 7 rather than Art. 9 would apply. See LeGall, Jean Francois. 2006. "When Is a Subsidiary a Permanent Establishment of Its Parent?” Tillinghast Lecture, New York University (forthcoming in Tax Law Review).

${ }^{9}$ Brian J. Arnold and Thomas E. McDonnell, Report on the Invitational Conference on Transfer Pricing: the Allocation of Income and Expenses Among Countries. Tax Notes. 13 December. 1377- 1381 (1993).

${ }^{10}$ Avi-Yonah, Clausing and Durst (2009), Allocating Business Profits FOR TAX Purposes: A Proposal to Adopt a Formulary Profit SPlit, Florida TAX ReV.

${ }^{11}$ This section is based on Avi-Yonah, Clausing and Durst (2009), supra. This article was written from a US perspective, but I have no reason to believe the situation in other countries is better. 
Most fundamentally, the ALS system ignores the fact that multinational groups of companies arise precisely in order to avoid the inefficiencies that arise when unrelated companies must transact with one another at arm's length. Multinational enterprises arise in large part due to organizational and internalization advantages relative to the efforts of unrelated, separate companies that seek to do business with one another. Such advantages mean that within multinational enterprises, profit is generated in part by internalizing transactions within the firm. Thus, for firms that are truly integrated across borders, holding related entities within the commonly controlled group to an "arms-length" standard for the pricing of intracompany transactions does not make sense, nor does allocating income and expenses on a country-by-country basis. In fact, a very similar logic was behind the use of FA for U.S. state governments and among the Canadian provinces; in an integrated economy, it does not make sense to attribute profits and expenses to individual jurisdictions using separate-entity accounting.

Second, the porosity of current transfer pricing rules creates an artificial tax incentive to locate profits in low-tax countries, both by locating real economic activities in such countries and by shifting profits toward more lightly taxed locations. It is apparent that U.S. multinational firms book disproportionate amounts of profit in low-tax locations. For example, Figure 1 shows the ten highest-profit locations for U.S. multinational firms in 2005, based on the share of worldwide (non-U.S.) profits earned in each location. While some of the countries are places with a large U.S. presence in terms of economic activity (the United Kingdom, Canada, Germany, Japan), seven of the topten profit countries are locations with very low effective tax rates.

Figure 1: Where Were the Profits in 2005 ${ }^{12}$

(profits as a percentage of the worldwide total)

\footnotetext{
12 In 2005, majority-owned affiliates of U.S. multinational firms earned \$336 billion of net income. This figure shows percentages of the worldwide (non-U.S.) total net income occurring in each of the top-10 income countries. Thus, each percentage point translates into approximately $\$ 3.4$ billion of net income. Effective tax rates are calculated as foreign income taxes paid relative to net (pre-tax) income. Data are from the Bureau of Economic Analysis (BEA) web page; 2005 is the most recent year with revised data available. The Bureau of Economic Analysis conducts annual surveys of Operations of U.S. Parent Companies and Their Foreign Affiliates. See AviYonah, Clausing and Durst (2009), Appendix A.
} 


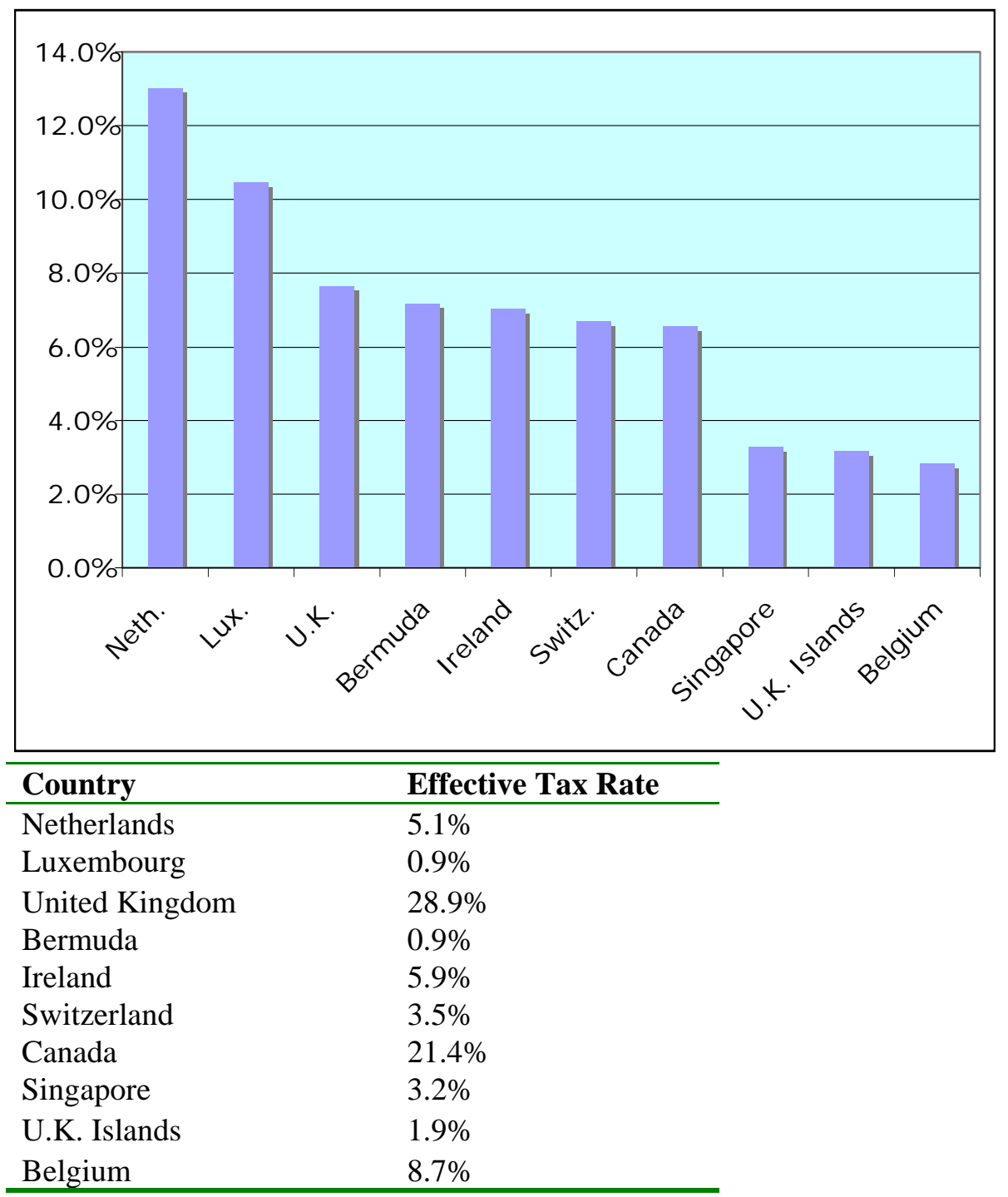

The literature has consistently found that multinational firms are sensitive to corporate tax rate differences across countries in their financial decisions. Estimates from the literature suggest that the tax base responds to changes in the corporate tax rate with an average semi-elasticity of about -2 ; thus, countries with high corporate tax rates are likely to gain revenue by lowering their tax rate. ${ }^{13}$ One recent study suggests that corporate income tax revenues in the United States were approximately 35\% lower due to income shifting in $2004 .{ }^{14}$

13 See de Mooij, Ruud A. 2005. "Will Corporate Income Taxation Survive?” De Economist. 153. 277-301 for an overview of this literature.

${ }^{14}$. This estimate is from Clausing, Kimberly A. 2008. "Multinational Firm Tax Avoidance and U.S. Government Revenue.” Working paper. The calculation is based on a regression of U.S. multinational firm affiliate profit rates on tax rate differences across countries. See Avi-Yonah, Clausing and Durst (2009), Appendix A for more details. 
This problem has worsened as U.S. corporate rates have become increasingly out of line with those of other countries. In the past twenty years, most OECD countries have lowered their corporate income tax rates, whereas U.S. rates have been relatively constant. This increasing discrepancy between U.S. rates and foreign rates likely results in increasing amounts of lost revenue for the U.S. government due to strengthening income shifting incentives.

Also, the literature suggests a substantial responsiveness of real economic activities to tax rate differences among countries. ${ }^{15}$ These findings imply both less activity in United States and less tax revenue for the U.S. government. However, the tax responsiveness of real activity is less immediately apparent in the data. For example, Figure 2 shows the top ten employment locations for U.S. multinational firms in 2005, based on the share of worldwide (non-U.S.) employment in each location. The high employment countries are the usual suspects - large economies with close economic ties to the United States. As the accompanying table indicates, tax rates are not particularly low for this set of countries.

Figure 2: Where Were the Jobs in 2005? ${ }^{16}$

(employment as a percentage of the worldwide total)

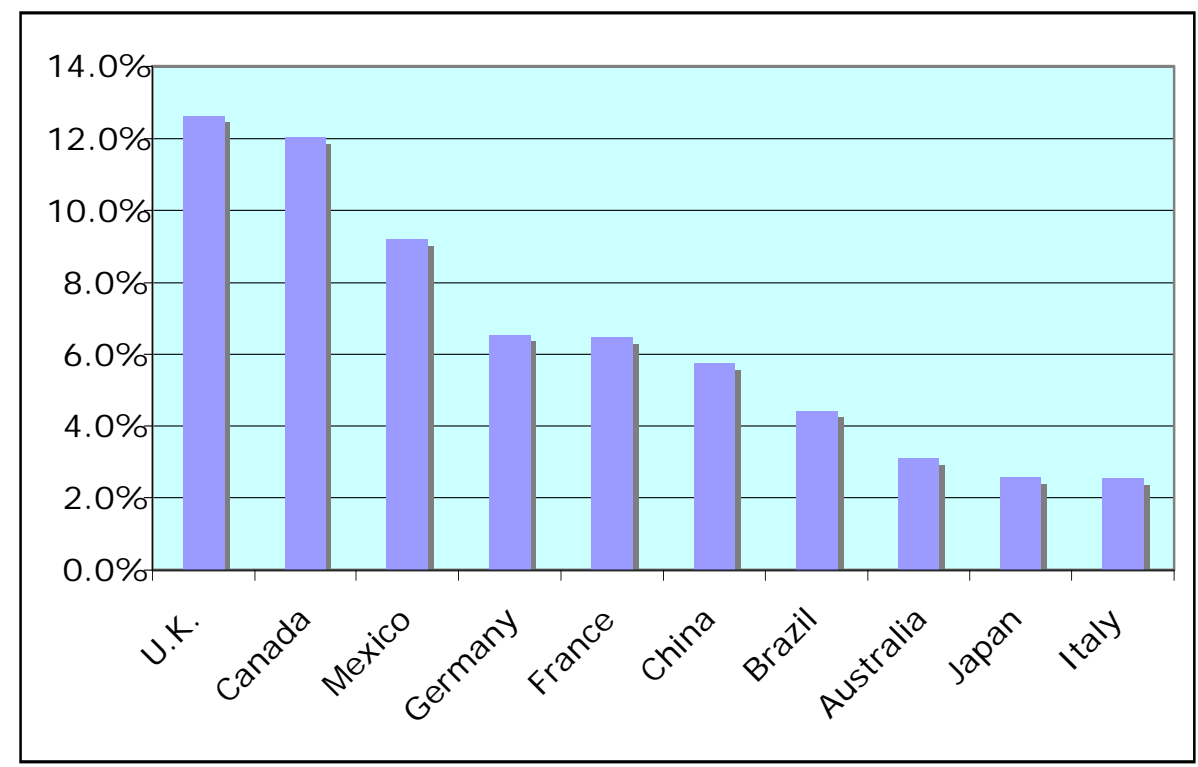

\footnotetext{
Country Effective Tax Rate

${ }^{15}$. See de Mooij (2005), supra.

${ }^{16}$ See note 12 supra for the basis of these data.
} 


\begin{tabular}{ll}
\hline United Kingdom & $28.9 \%$ \\
Canada & $21.4 \%$ \\
Mexico & $21.8 \%$ \\
Germany & $26.2 \%$ \\
France & $21.3 \%$ \\
China & $14.8 \%$ \\
Brazil & $18.1 \%$ \\
Australia & $12.1 \%$ \\
Japan & $34.7 \%$ \\
Italy & $24.9 \%$ \\
\hline
\end{tabular}

Third, the current system is absurdly complex. As Taylor notes, observers have described the system as "a cumbersome creation of stupefying complexity" with "rules that lack coherence and often work at cross purposes." ${ }^{17}$ Altshuler and Ackerman note that observers testifying before the President's Advisory Panel on Federal Tax Reform found the system "deeply, deeply flawed," noting that "it is difficult to overstate the crisis in the administration of the international tax system of the United States."18 Current transfer pricing rules have spawned a huge industry of lawyers, accountants and economists whose professional role is to assist multinational companies in their transfer pricing planning and compliance.

Fourth, particularly given the high U.S. corporate statutory tax rates, the U.S. corporate tax system raises relatively little revenue. For most OECD countries, revenues have increased as a share of GDP even as corporate tax rates have declined; the average OECD country receives about 3.25\% of GDP from corporate tax revenue by the end of the sample. Most observers attribute this trend to a broadening of the tax base for many OECD countries during this time period. For the United States, revenues are lower; although they fluctuate with the cyclical position of the economy, they tend to be closer to 2.25\% of GDP. There are several plausible reasons for the lower amount of U.S. revenue, including the increasingly aggressive use of corporate tax shelters, a narrower corporate tax base, and stronger incentives for tax avoidance, which tend to increase as the U.S. tax rate is high relative to other countries.

Finally, it is important to note that the problems with the current system derive not from rules at its periphery, but instead from a fallacy that lies at the system's central core: namely, the belief that transactions among unrelated parties can be found that are sufficiently comparable to transactions among members of multinational groups that they

17 Taylor, Willard. Testimony before the President's Advisory Panel on Federal Tax Reform. March 31, 2005. In Tax Notes (April 4, 2005) Doc 2005-6654.

18 Altshuler, Rosanne and Jonathan Ackerman. 2005. "International Aspects of Recommendations from the President's Advisory Panel on Federal Tax Reform.” International Tax Policy Forum Presentation. 2 December. 
can be used as meaningful benchmarks for tax compliance and enforcement. ${ }^{19}$ For example, if one wants to determine the "arm's length" level of profitability of a U.S. distribution subsidiary of a foreign manufacturer of automobiles, one identifies one or more independent U.S. distributors of automobiles operating in economically, similar circumstances and uses the income of the independent distributor or distributors to benchmark the income of the U.S. subsidiary.

Such an approach might well have made sense eighty years ago, when the legislative language underlying today's arm's length standard for income tax purposes was first developed. ${ }^{20}$ At that time, although multinational groups existed, available transportation and communications technology did not permit close centralized management of geographically dispersed groups. Therefore, members of multinational groups functioned largely as independent entities, and benchmarking their incomes or transactions based on uncontrolled comparables probably made good sense.

That situation changed, however, with the technological changes precipitated by the Second World War. Today, it is possible to exercise close managerial control over multinational groups, and these groups develop in all industries and geographic market segments in which the efficiencies of common control pose significant economic advantages. Moreover, in those industries and markets where common control poses advantages, it is typically economically infeasible to remain in the market using a noncommonly controlled structure (for example, by maintaining distributors that are economically independent of manufacturers). Therefore, in those markets in which multinational groups operate - that is, in those markets in which transfer pricing issues arise - it is unlikely that reasonably close "uncontrolled comparables" can be found. For example, to my knowledge, there are no independently owned distributors of massmarket automobiles in the United States; all of the distributors are owned by their manufacturers. $^{21}$

The same is true of virtually every other industry that is conducted on a large global scale. In sum, no matter how assiduously one performs "functional analyses" designed to identify "uncontrolled comparables" that are reasonably similar to members

19. This argument is presented in detail in e.g., Avi-Yonah (2006), supra, Langbein (1986), supra, and Durst, Michael C. and Robert E. Culbertson. 2003. "Clearing Away the Sand: Retrospective Methods and Prospective Documentation in Transfer Pricing Today.” Tax Law Review. 57. 37-84.

20 . For historical summaries see, e.g., Langbein (1986), Avi-Yonah (2006) and Durst \& Culbertson (2003) at 42-64.

21. Even some of the few apparent comparables that are found to exist often prove flawed. For example, often, such comparables arise in transitional situations in which, for example, an industry is entering a new market and operates temporarily through unrelated distributors, which after several years are acquired by the manufacturing company. Prices charged in such situations are unlikely to be representative of those that would be charged among members of commonly controlled groups. Similarly, one might find within a market independent distributors of small-volume "niche market" products within an industry, whereas the large-volume distributors will almost invariably be controlled by their manufacturers. See Durst \& Culbertson (2003) at 47-48. 
of multinational groups, one is rarely going to find them. Certainly, such comparables will not be - and have not been - found with sufficient regularity to serve as the basis for a workable transfer pricing system. If the transfer pricing rules are going to be made tolerably administrable, Congress will need to restate them on a basis other than that of reliance on uncontrolled comparables.

The results of the current system, which assumes the availability of useful comparables in an economic environment where they are very unlikely to be found, are predictable:

Companies and the government spend extraordinary sums each year on efforts at compliance and enforcement, largely through the preparation of "contemporaneous documentation" 22 by taxpayers and attempts at comprehensive examinations by the IRS involving some of the Service's most experienced and skilled personnel.

Despite the expense of compliance and enforcement, companies and the IRS typically are dramatically far apart in their determinations of arm's length pricing. Controversies routinely involve hundreds of millions of dollars and are resolved at amounts that resemble neither the government's nor the taxpayer's positions, thereby casting grave doubt on the conceptual soundness of the underlying rules. ${ }^{23}$

The inability to predict whether their positions will be sustained leaves companies and their investors with large areas of uncertainty in their financial statements.

The absence of clear standards for compliance, coupled with the ability under the arm's length standard to apportion income to low-tax countries through legal arrangements governing the sitting of

\footnotetext{
${ }^{22}$. See Treas. Reg. § 1.6662-6.
}

23. A 1992 study by the General Accounting Office concluded that less than 30\% of transfer pricing adjustments proposed by IRS examiners ultimately were upheld in subsequent proceedings. GAO (1992), supra. Similarly, in a recent multibillion dollar case settled out of court, the parties agreed on payment of 3.4 billion in settlement of pending transfer pricing claims; this represents concession of about $50 \%$ of the deficiency before the Tax Court, although since the settlement covered years in addition to those then pending before the court, the extent of IRS concession appears to have been larger. Overall, while results vary from case to case, the IRS typically recovers at trial only a small proportion of transfer pricing deficiencies that it has asserted. The lament by Judge Gerber in one case gives a good idea of the atmosphere to be found in this field of law, despite attempts to project an image of statistical science: "Once again, we are left stranded in a 'sea of expertise' and must navigate our own way through a complex record to decide what constitutes an appropriate arm's-length consideration.” H Group Holding, Inc. v. Comm'r, T.C. Memo 1999-334. The supply of very large, disputed transfer pricing adjustments does not seem likely to be exhausted soon. See Nutt, Audrey (2007). "News Analysis: Another Transfer Pricing Dispute in the Litigation Pipeline.” Tax Notes Today, January 23. 
intangibles and (more recently) the bearing of risk, make it impossible for Congress to predict with reasonable accuracy the actual amount of federal revenue that will be raised as a result of any particular corporate tax rate that Congress believes it has enacted.

(v) The fact that neither taxpayers nor enforcement authorities typically have clear standards for judging compliance means that issues involving very large amounts - billions of dollars - of federal revenue are resolved in examination, settled in Appeals, resolved in negotiations under tax treaties with foreign governments, negotiated through advance pricing agreements, or settled by attorneys out-of-court after examination. In most cases, federal privacy laws require that this decision-making occur outside the public eye. In my experience, those involved in this process have served their roles with both integrity and skill. Nevertheless, the resolution of issues involving such large amounts of money, without the benefit of clearly discernable decision-making standards and public scrutiny, is not healthy for the tax system.

(vi) A related problem is that the uncertain results under current transfer pricing law degrade the quality of tax practice on the parts of both taxpayer and government representatives, regardless of the high standards of practice that both sides seek to maintain. Both sides are tempted to state, as "starting points" for what is expected to be extended negotiation, positions that strain the edges of what most would consider reasonable. The resulting atmosphere contributes to a lessening of the publicly perceived credibility of both corporations and the government - a development that is seriously damaging to what will always remain a largely mixed economic system.

(vii) The vulnerability of the current transfer pricing system to the shifting of income based on intangibles ownership and risk-bearing makes necessary numerous additional complexities in the international tax system. If the current transfer pricing regime were replaced by a more formulary approach such as that suggested below, Congress could eliminate from the Code many or all of the "base company" provisions of subpart F, retaining only those portions of subpart $\mathrm{F}$ dealing with passive investment income. Considerable complexity would, of course, be retained, but much would be eliminated. Similarly, transfer pricing vulnerabilities probably constitute the most pressing argument against adoption of a territorial tax system. $^{24}$ Reforming transfer pricing rules could tip the policy-making balance in favor of adopting a territorial system, thereby permitting elimination of the grossly complex foreign tax credit system except as it

${ }^{24}$. Kleinbard, Edward D. (2007). “Throw Territorial Taxation From the Train.” Tax Notes Today, Feb. 6, 2007. 
relates to U.S. taxpayers' passive investment income (which would remain subject to the U.S. tax jurisdiction and for which credit rules would need to be retained). ${ }^{25}$ The current transfer pricing system therefore can be seen as the tail that wags the dog of much unnecessary tax complexity.

\section{Adopting Formulas in the Context of the ALS}

As stated above, these problems of the ALS are well known. However, they do not persuade opponents to abandon the ALS in favor of FA. Instead, the advocates of the ALS point to a list of asserted deficiencies of FA, including:

1. FA is inherently arbitrary;

2. FA will produce double taxation because some countries will apply the ALS and others FA, and the FA countries will each have a different formula;

3. FA requires an impossible to achieve uniformity of the tax base;

4. FA violates tax treaties;

5. FA will be impossible to enact because of the opposition of the multinationals and of countries that will lose from its implementation.

I believe that there is a good answer to each of these arguments, and have in fact replied to them at length elsewhere. ${ }^{26}$ However, I also realize that my answers are unlikely to persuade FA opponents. Thus, I want to use this article to propose a more modest step forward: adopting FA only in the context of ALS (rather than replacing the ALS with FA).

The basic problem arises in situations where there are no good comparables. If good comparables exist, the traditional methods (CUP, cost plus and resale price) can be used, and that would end the story. But as the OECD Guidelines acknowledge, in many cases good comparables are hard to find.

The next possible alternative under the OECD Guidelines is TNMM. However, TNMM requires a tougher comparability test than the US CPM, which is good because CPM has proven to be the most manipulable of the current methods: An informed economist working for a major accounting firm has told me he can achieve any result the client wants using CPM. CPM is also a huge source of transactional

${ }^{25}$. Id.

${ }^{26}$ Avi-Yonah, Clausing and Durst (2009, supra); on the treaties point see also Avi-Yonah, Reuven and Kimberly A. Clausing. 2008. "Reforming Corporate Taxation in a Global Economy: A Proposal to Adopt Formulary Apportionment.” In Jason Furman and Jason Bordoff, eds. Path to Prosperity: Hamilton Project Ideas on Income Security, Education, and Taxes. Brookings Institution Press. 319-44. 
complexity, a boon to the large accounting firms, and a problem for those who cannot afford their services. But the tougher OECD TNMM comparability standard means that TNMM cannot be applied in many cases in which CPM is used in the US.

This leaves Profit Split. Under Profit Split, comparables are used to allocate the return on routine functions. But that usually leaves a residual in place, which arises precisely because multinationals exist to earn a return that cannot be achieved in an arm's length relationship. That, as explained above, is why good comparables are hard to find.

Thus, the key issue in current transfer pricing is how to allocate the residual under the Profit Split method. The US regulations assume that the residual is the result of high profit intangibles and allocate it to where such intangibles were developed. However, this method is not helpful because (a) the OECD and the rest of the world rejects it, (b) it penalizes multinationals for conducting R\&D in the US, and (c) it encourages multinationals to enter into cost-sharing agreements that artificially shift profits to low tax jurisdictions. In addition, as the Bausch \& Lomb court stated, if the value of the intangible results from the fact that two parties are related, that added value is distinct from where it was developed.

If the US approach is rejected, the question is how to allocate the residual. The OECD Guidelines are silent on this issue. This presents an opportunity: Perhaps in this context, it should be possible to adopt a formula to allocate the residual.

One needs to realize that if there are no comparables (by definition) and the residual results from the relationship between the parties and would disappear if they were unrelated, then the ALS is meaningless and any allocation is arbitrary. Under these circumstances the key is to adopt the formula that is most likely to achieve consensus.

In the unilateral US context, I supported a sales-based formula similar to the destination-bass formula for VAT. This choice of formula favors exports and therefore is likely to be politically popular, and it favors the US because of our trade deficit. $^{27}$ In the OECD context, I would prefer a more balanced formula with three components- payroll, tangible assets and sales.

These three components are of course the traditional US state FA formula. This formula has proven to be remarkably successful, since in addition to the US states, it is also the basis for the global dealing regulations in the US and OECD, and is a leading candidate for the CCCTB formula. I believe it makes sense because each of its elements is objective (payroll and sales are transactions with outside parties, and while tangible assets depend on valuations, there is a lot of experience with assetbased formulas, such as the US interest allocation formula). Intangibles are excluded, but in my opinion that is appropriate because (a) their value results from physical and human capital and from the market and those elements are included, and (b) you cannot allocate their value and trying to include them invites manipulation.

${ }^{27}$ Avi-Yonah and Clausing (2008), supra. 
Thus, I would propose that in hard transfer pricing cases, in which no comparables can be found beyond the return on routine functions, the OECD endorse using the traditional three factor state formula to allocate the residual under the Profit Split method.

I believe this proposal addresses the problems with FA outlined above:

1. While the formula is arbitrary it relates to economic reality, and any allocation is arbitrary in the absence of comparables. The current OECD Guidelines are also arbitrary in not allocating residuals.

2. It is unlikely that this outcome would lead to more double taxation than what already occurs for residuals under the ALS. If the US allocates residuals based on location of R\&D and other countries disagree, double taxation is already a threat. Disputes can be resolved using the new arbitration provision under the OECD model.

3. If the OECD accepts the residual formula under ALS, it does not violate treaties and it can be handled in the context of Article 9.

4. Since it is only a residual formula, the base has already been defined under ALS.

5. A balanced formula is less likely to produce consistent losers.

\section{Conclusion: A Plea for Dialogue.}

The OECD has recently moved in the direction of applying the ALS and the Transfer Pricing Guidelines to branches as well as subsidiaries. Richard Vann and others have criticized this move but it is a fait accompli.

The problem with this proposal is that it treats branches as if they were subsidiaries and applies to them the ALS without acknowledging that the current ALS is imperfect. ${ }^{28}$ A better move would have been to treat subsidiaries as if they were branches, moving the system closer to FA. As stated above, treating a multinational as a single economic entity without distinguishing between its constituent units is an acknowledgement of economic reality.

As the recent OECD move on attribution of profits to PEs shows, opponents of FA are unlikely to agree. However, some progress may be possible along the lines suggested by this article, as indicated by the following message from Hugh Ault of OECD: $:^{29}$

Reuven,

Thanks for the note. I have talked to Mary [Bennet] and Caroline [Silberztein] about

${ }^{28}$ Avi-Yonah and Clausing, in Lang (2008).

${ }^{29}$ E-mail from Hugh Ault to Reuven Avi-Yonah, April 8, 2009, reprinted with permission of its author. 
your thoughts on using residual profits splits in "hard" cases under the TPG and the current status of things is as follows. Under the 1995 TP Guidelines, profit split is to be used in "hard" cases e.g. where transactions are highly integrated, or where both parties to a transaction contribute valuable, unique intangibles which make one-sided methods inapplicable. As you know, the OECD is currently considering removing the last resort status of the profit methods. In particular, given the pace of globalization, the increasing role of intangibles and the implementation by MNE groups of highly integrated transactions, profit split clearly has a role to play. On the other hand, the OECD does not favor using a profit split to remunerate simple, benchmarkable functions such as contract manufacturing or distribution activities, because simpler and more reliable one-sided methods can be applied to those and you can imagine that the countries where these simple functions are performed are not keen to share in the losses in the current economic context.

In practice, the residual or combined profit is in effect allocated on the basis of an allocation key. In the OECD view, this allocation key is not pre-established and its choice in a particular case may either be supported by external market data (e.g. profit split percentages observed among independent enterprises with comparable functions) or be based on the relative value of the contributions of each party. Whatever the allocation key, the OECD considers that the objective is to approximate the division of profits that independent enterprises would have agreed to in similar circumstances.

The critical point here is that residual profit (or loss) is considered to be attributable to valuable, unique contributions, such as valuable, unique intangibles. In effect, the simple, benchmarkable contributions can generally be remunerated using either a traditional method or TNMM. Because the contributions that lead to the making of the residual are deemed to be unique and valuable, they don't seem to be good candidates for a safe harbor type approach. A safe-harbour type approach might be considered for simple, low value added functions (see the services Regs in the US) as a matter of risk assessment and costs-benefit analysis, but not for the unique, valuable intangibles that make the residual. For the latter, the OECD thinks that it is important to ensure that the allocation key is one that reflects the respective values of these contributions, on a case-by-case basis. For instance, it may be R\&D expenses where the profit split is used to remunerate parties which contribute R\&D efforts, or marketing expenditure if the parties contribute marketing efforts, or a mixed of both if one party contribute $R \& D$ and the other marketing efforts. If parties contribute existing intangibles, then asset-based allocation keys may be more appropriate than expense-based ones, etc..

In the discussion draft on transactional profit methods that was released in January 2008, the OECD proposed to expand the guidance on the practical application of profit methods and there is an Issues Note (Note No. 9) on how to split the profit in a profit split (see http://www.oecd.org/dataoecd/18/48/39915180.pdf, pp.65 and following). For instance, with respect to allocation keys, the OECD tentatively concluded that it is not desirable to establish a prescriptive list of criteria or allocation keys. It is however possible to identify a number of general requirements that should 
be satisfied by the criteria or allocation keys used, i.e. they should:

- Be consistent with the functional analysis of the controlled transaction under review, and in particular reflect the allocation of risks among those parties,

- Be consistent with those which would have been agreed between independents in comparable circumstances, given the profit split method seeks to determine the division of profits that independent enterprises would have expected to realise from engaging in the transaction

- $\quad$ Be independent of transfer pricing policy formulation, i.e. they should be based on objective data (e.g. sales to unrelated parties), not on data relating to the remuneration of controlled transactions (e.g. sales to related parties),

- Be consistent with the type of profit split approach (e.g. contribution analysis, residual analysis, or other; ex ante or ex post approach),

- Be capable of being measured in a reasonably reliable manner.

The Working Party is currently working on revising Chapter III of the TP Guidelines to incorporate a large part of the conclusions that were tentatively reached in this discussion draft. We expect the proposed revision of Chapters I-III of the TP Guidelines to be released for public comment in fall 2009.

This should give you plenty to work with and is consistent with your idea of using profit split in "hard" cases. If you need any more information or would like to talk further about working out these ideas and any approaches you might have we can be in contact.

Best

Hugh

This is hopeful, because given the long-standing and intractable nature of the ALS/FA debate, the best we can hope or is for the two sides to begin to talk to each other. This article represents a plea for such a dialogue, and an attempt to reach common ground. I hope it will be the beginning of a fruitful discussion. 